\title{
A Simulation Study to Understand the Efficiency Analysis of Multiple Injectors for the Double Compression Expansion Engine (DCEE) Concept
}

\author{
Author, co-author (Do NOT enter this information. It will be pulled from participant tab in \\ MyTechZone) \\ Affiliation (Do NOT enter this information. It will be pulled from participant tab in MyTechZone)
}

Copyright $\odot$ 20xx SAE International

\begin{abstract}
Heavy-duty vehicles face increasing demands of emission regulations. Reduced carbon-dioxide $\left(\mathrm{CO}_{2}\right)$ emission targets motivate decreased fuel consumption for fossil fuel engines. Increased engine efficiency contributes to lower fuel consumption and can be achieved by lower heat transfer, friction and exhaust losses. The double compression expansion engine (DCEE) concept achieves higher efficiency, as it utilizes a split-cycle approach to increase the in-cylinder pressure and recover the normally wasted exhaust energy. However, the DCEE concept suffers heat losses from the high-pressure approach. This study utilizes up to three injectors to reduce the wall-gas temperature gradient rendering lower convective heat losses. The injector configuration consists of a standard central injector and two side-injectors placed at the rim of the bowl. An increased distance from side-injector to the wall delivered lower heat losses by centralizing hot gasses in the combustion chamber. Computational fluid dynamics (CFD) simulations investigated two different piston bowls, in a heavy-duty diesel engine, to obtain in-cylinder conditions for one, two -and three-injector concepts. One-dimensional (1D) simulations then used the CFD data to obtain the complete efficiency analysis of the DCEE concept. The results showed that the three-injector case improved the brake thermal efficiency and reduced the heat transfer losses, compared to the two-injector and single-injector cases. In particular, the three-injector case resulted in a high indicated and brake thermal efficiency of $58.5 \%$ and $54.2 \%$, respectively.
\end{abstract}

\section{Introduction}

Current compression ignition (CI) engines require a technological breakthrough to further improve the overall engine efficiency and simultaneously lower the engine-out emissions. Although the emissions of nitrogen oxides $\left(\mathrm{NO}_{\mathrm{x}}\right)$, particulate matter $(\mathrm{PM})$, carbon monoxide (CO) and unburnt hydrocarbon (UHC) have shown a considerable decline over the past few years [1]; however, a necessity to further reduce these emissions is a need of the hour. In particular, previous study reported the on-road carbon-dioxide $\left(\mathrm{CO}_{2}\right)$ emissions for the heavy-duty diesel engines to be around $25 \%$ in the European market [2], and the numbers are projected to further increase by 2040 [3].

Low temperature combustion (LTC) regimes have been investigated in various previous studies, which aim to increase the thermodynamic efficiency and reduce the flame temperature, below the thresholds of thermal NO and soot formation. These include homogenous charge compression ignition (HCCI) [4-8], reactivity controlled compression ignition (RCCI) $[9,10]$ and Page 1 of 11 partially premixed combustion (PPC) [11-15]. All these combustion regimes claimed overall lower heat transfer losses due the lower temperature maintained by highly diluted bulk gas fractions; however the complete conversion of thermodynamic efficiency into brake thermal efficiency (BTE) is a challenging concern. This is because of the unavoidable losses incurred during the gas exchange, combustion and friction in a conventional fourstroke engine.

Split-cycle engine concepts can solve this issue which include, the series XIV engine [16], the compact compression ignition engine [17], Scuderi engine [18], the CryoPower engine [19], and General motors compound engine [20]. However, some of these concepts resulted in a lower BTE while for the other concepts, no published data is available. A promising split-cycle engine concept is double compression expansion engine (DCEE) [21-23], which can be a viable solution to optimize the individual efficiencies. Due to overexpansion and an additional compression/expansion cylinder of the DCEE concept, the exhaust and friction losses can be reduced, respectively. Additionally, the higher load limit can be extended due to the increased intake boost capability using the compression cylinder. However, the DCEE concept depends on a high effective compression ratio to achieve high engine efficiency and therefore a high peak cylinder pressure (PCP) is required, which can increase the heat transfer losses.

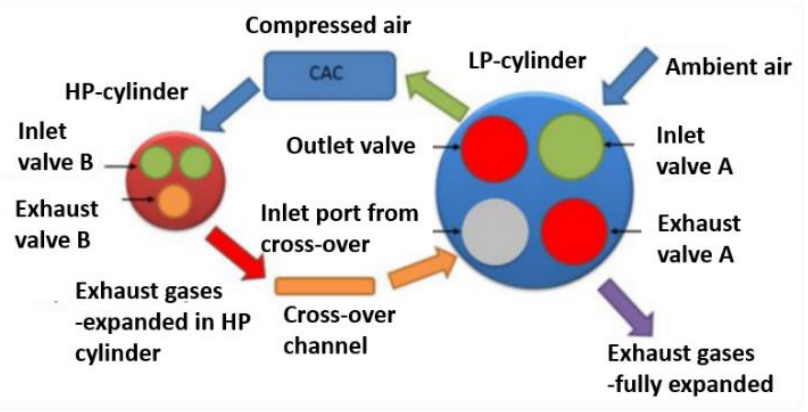

Figure 1. The 4-4 layout of DCEE concept [21]

In the 4-4 layout of DCEE concept, each cylinder operates in four strokes per cycle [21]. This layout is shown in Figure 1 which includes: a large-volume, low-pressure (LP) unit compressing the intake air and expanding the leftover exhaust gases; a highpressure (HP) unit, where a second compression, combustion, and a first expansion occurs; a low-pressure tank supplying compressed air to the HP unit; a charge air cooler (CAC) to reduce the high temperature before the HP unit; and a cross-over channel to supply 
hot exhaust gases to the LP unit for the second expansion. The compressed air from the LP unit flows to the HP unit through the LP tank and the CAC, which enables an isobaric transfer of compressed gases and reduced temperature for lower heat losses. The HP unit achieves higher PCP by using higher intake air pressure generated by the LP unit, which in combination with a diluted air-fuel mixture results in high engine efficiency. Because of only two cylinders, the expansion of compressed gases is not fully achieved as the compression and expansion processes occurs in the LP unit and another limitation is the choked air-flow in the LP cylinder head.

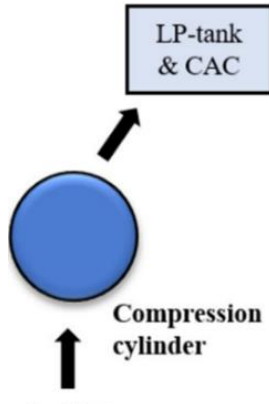

Ambient air

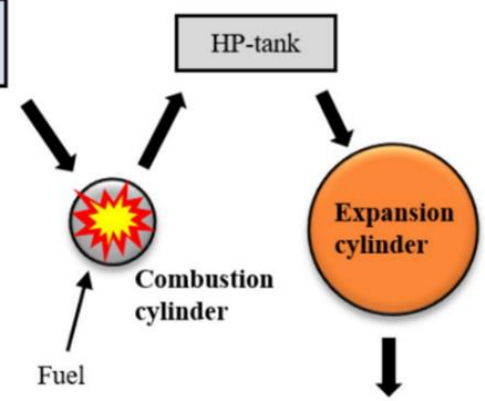

Fully expanded exhaust gases
Figure 2. The 2-4-2 layout of DCEE concept [23]

To alleviate these concerns, a 2-4-2 layout of DCEE concept was proposed in which the LP unit was further splitted into two 2-stroke compressor and expander units [23], as shown in Figure 2. This means that instead of a single LP unit performing both the compression and expansion strokes, these two cylinders in this layout can individually perform this task. The combustion cylinder, however, operates in a similar way as that of HP unit in the 4-4 layout. Compared to one intermediate tank in 4-4 concept, this concept comprised of two tanks: LP and HP tank on either side of the combustion cylinder. The remaining work from the high-pressure and high-temperature gases using the combustion cylinder can be extracted to atmospheric conditions using the expander cylinder through over-expansion, which however, is dependent on the expansion cylinder size, expansion ratio, in-cylinder pressure maintained in the HP tank, and the optimized valve-timings. The high PCP in the combustion cylinder will result in increased friction losses; however due to lower in-cylinder pressure in the compression and expansion cylinder, the overall friction losses can be reduced, thereby resulting in increased mechanical efficiency.

From a previous one-dimensional (1D) simulation study, DCEE concept resulted in BTE of 56\% and 54.5\% at an air-excess ratio of 3 and 1.2, respectively [21]. The efficiency gain can be further improved by insulating the intake and exhaust ports i.e., reduced heat transfer losses [24]. Furthermore, lessened flame-wall interaction reduces the combustion cylinder heat losses [25]. This can be achieved by optimizing the fuel injection parameters such as increased injection duration or lower injection pressure. However, attaining high-load conditions using this strategy has limitations. An alternative solution to reduce the heat losses was proposed in a previous study through the implementation of multiple injectors [25]. This study showed a heat loss-reduction of

Page 2 of 11
1.5 - 2 percent points in a CI engine. Other multiple injector studies suggested further heat loss reduction of up to 4.2 percent points depending on the piston-bowl geometry and operating conditions [26].

With the reduced heat losses from multiple injectors, the present study aims to use a three-dimensional (3D) computational fluid dynamics (CFD) tool and one-dimensional (1D) GT-Power simulations to further explore this concept for the full DCEE cycle. The geometry was based on a heavy-duty Volvo D13 diesel engine. The study investigated three injector configurations as follows: one centrally mounted injector (the single-injector case); two sideinjectors placed at the rim of the bowl (the two-injectors case); and all three injector together (the three-injectors case). The 1-D simulations utilized the CFD in-cylinder pressure and rate of heat release (RoHR) traces to represent the combustion cylinder of DCEE concept, followed by a full DCEE-cycle analysis.

\section{Methodology Approach}

\section{CFD Simulations}

3D computational fluid dynamics (CFD) simulations evaluated the DCEE combustor performance based on results from previous studies [27,28]. The software Converge, version 2.4, used the Reynolds-averaged Navier-Stokes (RANS) approach to find the combustor's convective heat transfer losses and its indicated efficiency. The domain included only the combustion chamber, since the 1D simulations include the combustor intake and exhaust lines, as discussed in the GT-Power Simulation section.

This study utilized both grid embeddings, at the wall and injectors, and adaptive mesh refinement (AMR), in combination with a base grid size of $2 \mathrm{~mm}$ in all directions, for accurate results. The wall embeddings aimed for a $\mathrm{y}+$ value inside the log-law region to improve the heat transfer calculations. Temperature and velocity gradients decided the AMR where high gradients lead to a local mesh refinement. Figure 1 shows the standard bowl-geometry mesh at different cycle times where the refinements become evident after the start of injection.

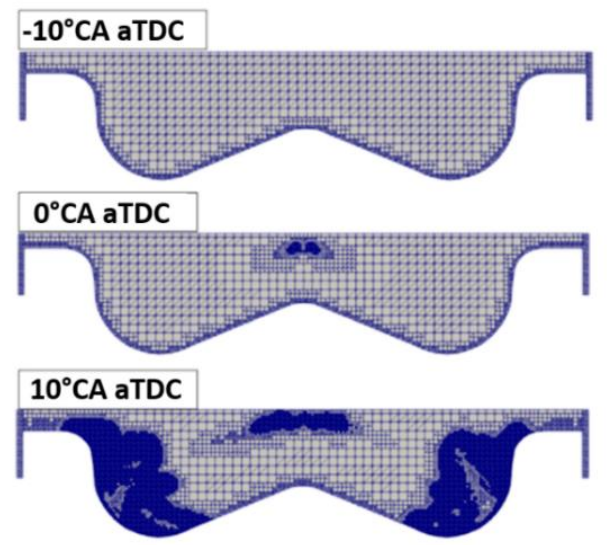

Figure 1. Mesh for standard bowl-geometry at different start of injection timings [29] 


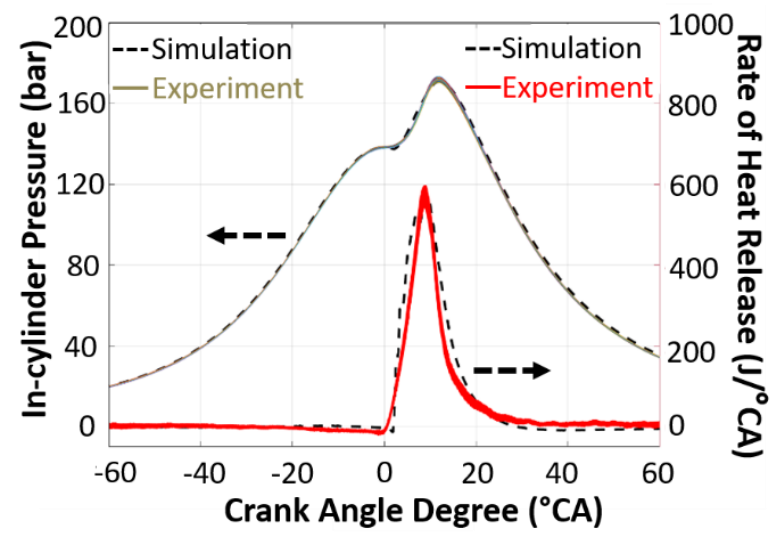

Figure 2. The in-cylinder pressure and rate of heat release (RoHR) traces of the CFD simulations validated against the experimental data for the single injector case [27]

An n-heptane mechanism [30] accounted for the chemistry where the injected diesel was assumed n-heptane upon evaporation. Thus, the simulations assumed liquid diesel injection followed by gaseous n-heptane, with an adjusted lower heating value. The spray breakup followed the Kelvin-Helmholtz Rayleigh-Taylor (KH-RT) approach [31]. In combination with the RANS, a renormalized group k-epsilon model calculated the flow turbulence. The ignition and combustion utilized a SAGE combustion model which maps the grid into bins based on temperature and equivalence ratio differences. Finally, an Amsden model [32] calculated the heat transfer losses based on the law of the wall with an assumption of constant wall temperatures set at $500 \mathrm{~K}$.

Figure 2 shows the CFD validation against metal engine experiments based on the in-cylinder pressure and the rate of heat release (RoHR) for the single-injector standard bowl case. For this study, conventional diesel combustion (CDC) mode was used instead of isobaric combustion, which has shown to have potential benefits for the DCEE concept $[33,34]$. However, isobaric combustion, which is achieved through multiple injections will be considered for our future investigations. To adjust the simulation results, the following measures were taken: compression ratio adjustment from 11.5 to 11.41 ; start of injection adjustment from $1{ }^{\circ} \mathrm{CA}$ aTDC to $-0.2^{\circ} \mathrm{CA}$ aTDC since a square injection profile was used; and an injection duration adjustment from $7.2^{\circ} \mathrm{CA}$ to $8.5^{\circ} \mathrm{CA}$.

\section{Tested Conditions, Injector Configuration and Chamber Geometry}

All CFD simulations in this study adhere to simulations performed in our previous work [26,27]. The CFD simulation conditions follow the combustion cylinder of the DCEE concept [35] with: a low compression ratio of 11.5; a high intake temperature of 464.15 $\mathrm{K}$; and high intake pressure at 5 bar. Otherwise, the parameters follow typical heavy-duty CI engine middle-load conditions, where a standard Volvo D13 single-cylinder engine built the baseline combustion chamber geometry. Table 1 lists all combustion cylinder parameters.
The present study includes three different injector configurations: a single-injector reference case; a side-injectors only case; and a three-injector case. Figure 3 shows the injector configurations where each side injector uses half the central injector flow rate. The total injected fuel (conventional diesel) of $150 \mathrm{mg}$ ( $30 \mathrm{bar}$ FuelMEP) was kept constant for all cases. The multiple-injector cases split the fuel amount equally between the injectors whereas the two-injector case injected $75 \mathrm{mg}$ from each side-injector, and the three-injector case injected $37.5 \mathrm{mg}$ from each side-injector and $75 \mathrm{mg}$ from the central injector.

Table 1. Engine parameters and operating conditions

\begin{tabular}{|c|c|c|}
\hline \multicolumn{2}{|c|}{ Cylinder volume (single cylinder) } & 2.13 liter \\
\hline \multicolumn{2}{|l|}{ Stroke } & $158 \mathrm{~mm}$ \\
\hline \multicolumn{2}{|l|}{ Bore } & $131 \mathrm{~mm}$ \\
\hline \multicolumn{2}{|c|}{ Connecting Rod } & $267.5 \mathrm{~mm}$ \\
\hline \multicolumn{2}{|c|}{ Compression Ratio } & 11.5:1 \\
\hline \multicolumn{2}{|l|}{ Engine Speed } & $1200 \mathrm{rpm}$ \\
\hline \multicolumn{2}{|c|}{ Intake Temperature } & $464.15 \mathrm{~K}$ \\
\hline \multicolumn{2}{|c|}{ Nozzle hole diameter } & $240 \mu \mathrm{m}$ \\
\hline \multirow{2}{*}{$\begin{array}{l}\text { Number of } \\
\text { injector holes }\end{array}$} & Central & 6 \\
\hline & Side & 3 (each) \\
\hline \multicolumn{2}{|c|}{ Standard umbrella angle } & 145 degrees \\
\hline \multicolumn{2}{|l|}{ Lambda } & 3.2 \\
\hline \multicolumn{2}{|l|}{ Intake Pressure } & $\sim 5$ bar \\
\hline \multicolumn{2}{|c|}{ Exhaust Pressure } & $\sim 8.75$ bar \\
\hline
\end{tabular}

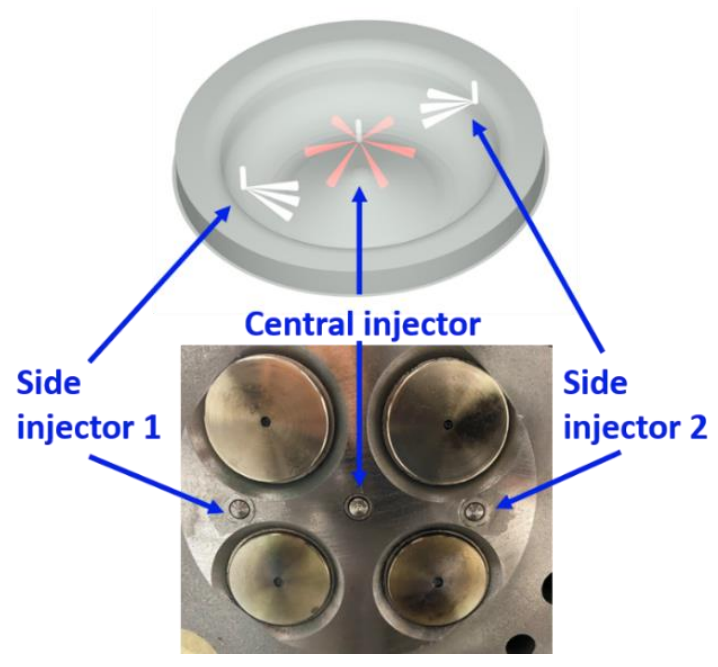

Figure 3. The bowl-geometry at top-dead center (TDC) with one central injector with six holes and two outer side injectors with three holes each [26], at the top. Bottom picture shows the cylinder head of the Volvo D13 engine, depicting the location of all three injectors 


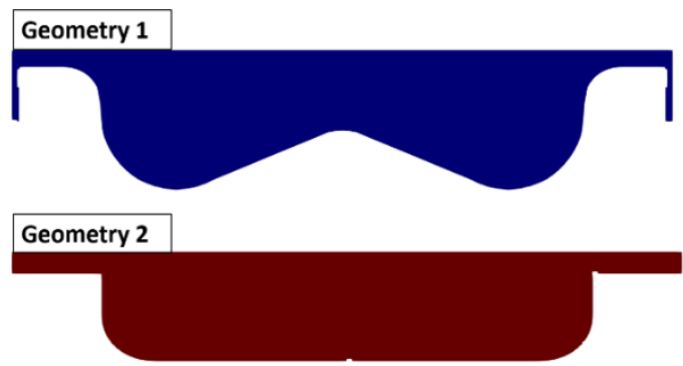

Figure 4. Two different bowl shapes with a standard piston-bowl i.e., Geometry 1 and flat piston-bowl i.e., Geometry 2 [27]

Table 2. Summary of cases

\begin{tabular}{|l|l|l|}
\hline & Number of injectors & Piston shape \\
\hline Case 1 & 1 (central) & Standard \\
\hline Case 2 & 2 (side injectors) & Flat \\
\hline Case 3 & 3 (central and side injectors) & Standard \\
\hline
\end{tabular}

The single-injector and three-injector cases used the standard piston-bowl while the two-injector case included a flat piston-bowl i.e. removed pip to reduce heat losses with side-injection only, as shown in Figure 4. This followed from a previous study [27] where a flat piston-bowl reduced the heat losses for two-injector cases. The three-injector case used the standard piston-bowl to increase the distance from central injector to wall. The flat piston-bowl renders a smaller distance from piston to head to keep a constant compression ratio, therefore leading to a shorter distance from central injector to piston. Table 2 summarizes all cases.

\section{One-Dimensional Simulations}

The software GT-Power, version 2019, simulated two 1D models, one for the combustion cylinder and one for the full DCEE concept.

The combustion cylinder mimicked the geometrical parameters of the Volvo D13 diesel engine, listed in Table 1. Previous studies [26-28] provided the PCPs for this 1D simulation, as depicted in Figure 5. A non-predictive combustion model calculated the burn rate from CFD cylinder pressure analysis. Here, the model adjusted the in-cylinder pressure and heat release rate to match the CFD data, before feeding it to the main DCEE model. It is to be noted that in 1D simulations, the cylinder pressure analysis does not allow the injection events of multiple direct fuel injectors during the valve closing period. Therefore, Case 2 uses a single 6-hole injector while Case 3 uses a single 12-hole injector. This study assumes little or no effect of these injector assumptions due to kept fuel amount and injection timings during the 1D simulations.

For the full DCEE concept, the model base followed previous studies [21,35], with a 2-4-2 layout including a 2-stroke compressor, a 4-stroke combustion cylinder and a 2-stroke expander, as shown in Figure 6. An LP tank after the compression cylinder and an HP tank before the expander performed the gas exchange, without pressure loss because of the large tank volumes. Table 3 shows the geometrical parameters selected.

Table 3. Engine geometry selected for DCEE model

\begin{tabular}{|l|l|l|}
\hline \multirow{5}{*}{$\begin{array}{l}\text { Displacement } \\
\text { volume }\end{array}$} & Compression cylinder & 3.25 liter \\
\cline { 2 - 3 } & Combustion cylinder & 2.13 liter \\
\cline { 2 - 3 } & Expander cylinder & 5.82 liter \\
\cline { 2 - 3 } & Total & 11.2 liter \\
\cline { 2 - 3 } & LP tank & 32.4 liter \\
\cline { 2 - 3 } Compression ratio & HP tank & 32.4 liter \\
\hline & Compression cylinder & $15: 1$ \\
\cline { 2 - 3 } & Combustion cylinder & $11.5: 1$ \\
\cline { 2 - 3 } & Expander cylinder & $15: 1$ \\
\hline
\end{tabular}

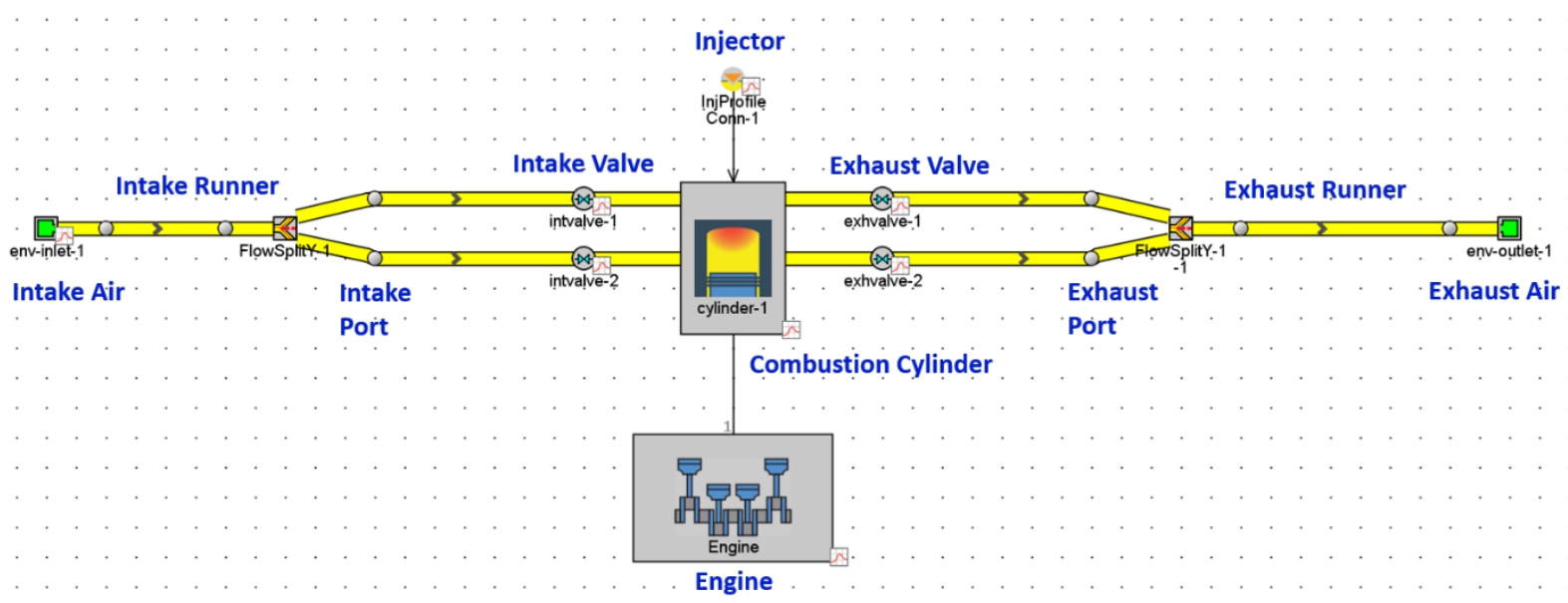

Figure 5. The general layout of combustion cylinder or conventional 4-stroke engine modelled in GT-Power

Page 4 of 11 


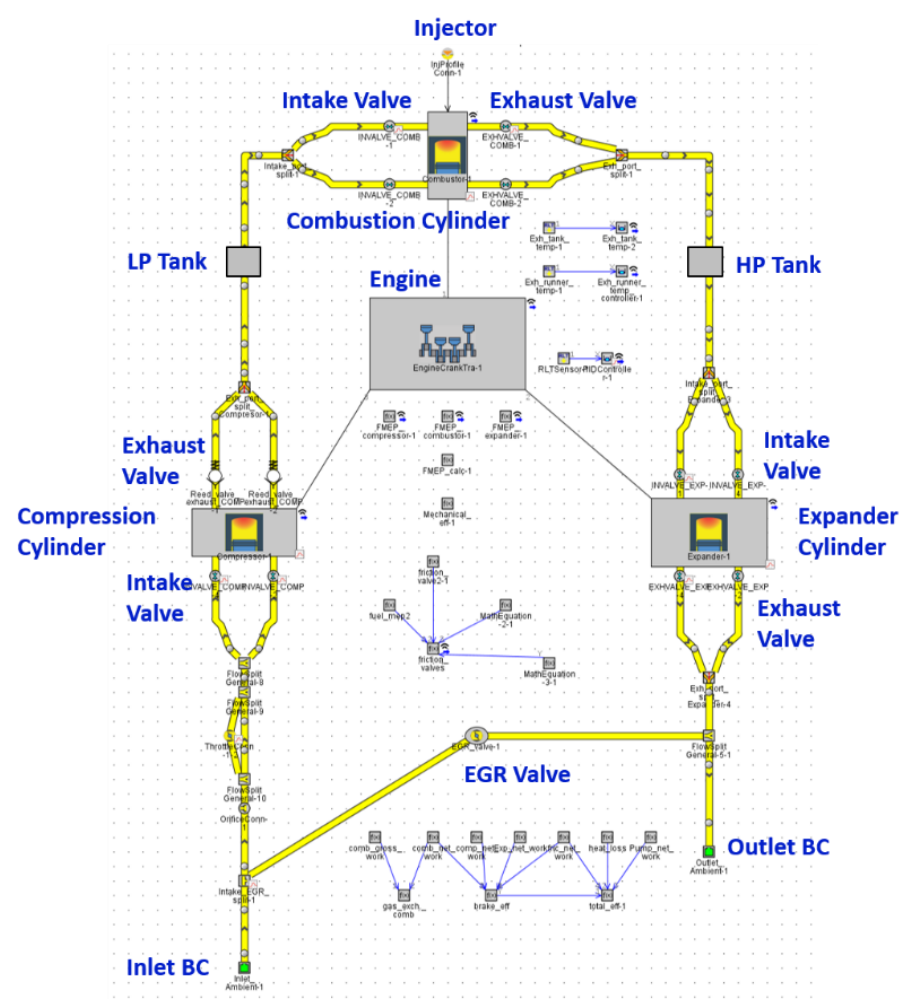

Figure 6. The 2-4-2 layout of double compression expansion engine (DCEE) concept modelled in GT-Power

While the displacement volume and compression ratio of the combustion cylinder was fixed, the geometry of other cylinders were selected on a trial-and-error basis to match the in-cylinder pressure, RoHR, air-excess ratio, inlet pressure and temperature, and exhaust pressure. Also, these geometrical parameters were kept consistent for all the cases. Table 3 shows that the expander volume remains larger than the other cylinders such that over-expansion can be achieved to atmospheric conditions. It is to be noted that these geometrical parameters are optimized based on the given PCP from CFD study. However, different PCP, levels of intake/exhaust pressure, and early or late intake/exhaust valve timings can change these parameters, which will be addressed in our future investigations.

The 1D simulations used the Woschni GT heat transfer model. This model calculate the in-cylinder convective heat transfer based on classical Woschini correlation without swirl [36]. For each case, the heat convection multiplier was adjusted to match the CFD incylinder pressure and RoHR. Due to the unavailability of experimental data for compressor and expander units, the heat convection multiplier was kept at 1.0, similar to previous DCEE studies $[23,35]$. This study assumes insulated tanks and intake and exhaust ports with a heat transfer multiplier of 0 . Thus, the model calculates no heat transfer losses for these parts.

The Chen-Flynn model calculated the friction losses using equation 1 as:

Page 5 of 11
$\mathrm{FMEP}=\mathrm{FMEP}_{\mathrm{Const}}+\mathrm{A} \cdot \mathrm{P}_{\mathrm{Cyl}, \max }+\mathrm{B} \cdot \mathrm{c}_{\mathrm{p}, \mathrm{m}}+\mathrm{C} \cdot \mathrm{c}_{\mathrm{p}, \mathrm{m}}^{2}$

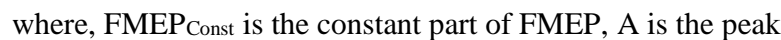
cylinder pressure factor, $\mathrm{B}$ is the mean piston speed factor, $\mathrm{C}$ is the mean piston speed squared factor, $\mathrm{c}_{\mathrm{p}, \mathrm{m}}$ is the mean piston speed and $\mathrm{P}_{\text {cyl,max }}$ is the maximum cylinder pressure.

However, not enough information was available in the existing literature regarding these constants, particularly for the compression and expansion cylinders. To simplify this issue, a linear friction model was implemented, similar to previous studies [22,23,37], given by equation 2 as:

$\mathrm{FMEP}=\mathrm{PCP} *(\mathrm{~A} / \mathrm{B})$

where, A and B were fixed at 1.2 and 200, respectively based on the assumption that FMEP is 1.2 bar at PCP of 200 bar. More details about this friction model can be found in previous work $[22,23,37]$.

\section{Results and Discussion}

\section{In-cylinder Pressure Analysis}

Figure 7 shows the in-cylinder pressure and rate of heat release (RoHR) traces comparing 1D GT-Power simulations for singleinjector (orange line), two-injector (blue line), and three-injector (green) cases with 3D CFD cases (black lines). The fuel injection timing, duration and input fuel energy was kept constant, for all the studied cases.

For all cases, the 1D in-cylinder pressure and RoHR results agrees closely with the CFD data. Case 1 and 2 render similar RoHR, while the increased flow rate of Case 3 gives a faster RoHR with a higher peak. This is in line with previous studies [27,28].

Figure 8 highlights the combustion phasing and burn duration for the three studied cases. The combustion phasing, i.e., CA2 represents the crank angle degree corresponding to $2 \%$ of heat released, while the initial and final burn duration is represented by CA0-50 and CA0-90, respectively. The reason for keeping injection timing constant, instead of combustion phasing is to understand the combustion behaviour for different cases. Moreover, staged injections using different injectors to achieve similar CA50 is impossible to model using 1D simulations. How the injection timings impact the combustion and the associated heat transfer losses, can be found in a previous work [28]. Case 2 and 3 renders a faster combustion as follows: the early combustion, CA2, remains lower for both Case 2 and 3 compared to Case 1; CA0-50 shows a declining trend (indicating faster combustion) with an increased number of injectors; and CA0-90 shows a similar declining trend with an increased number of injectors. These results suggest an improved mixing when multiple injectors are utilized at the present load conditions. 

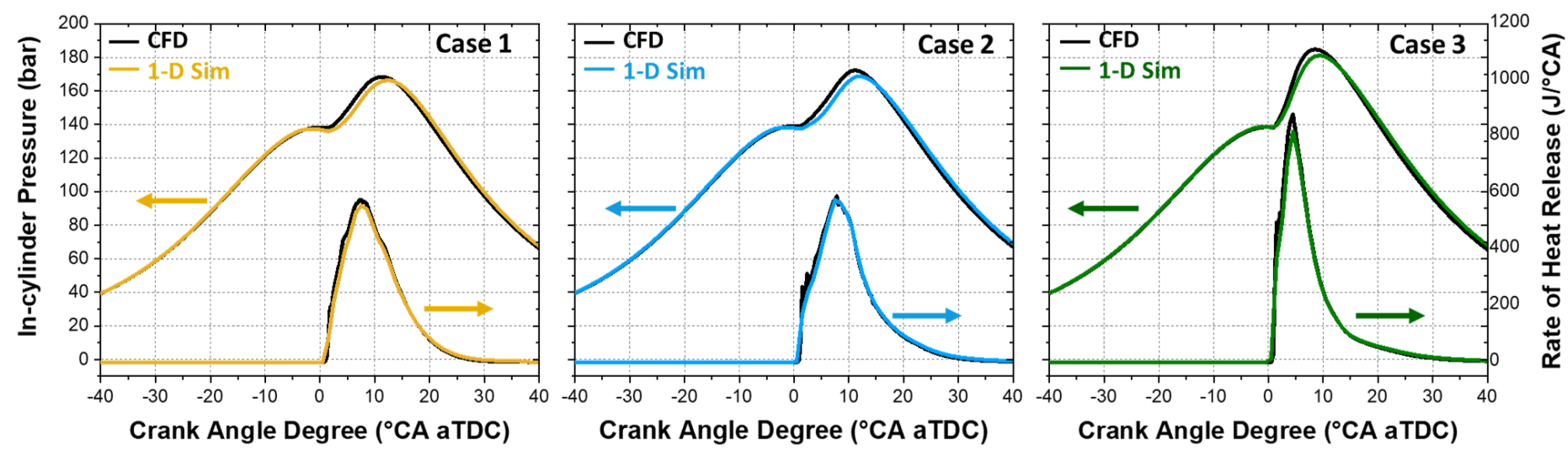

Figure 7. In-cylinder pressure and rate of heat release (RoHR) traces comparing 1D and 3D simulation results for the three studied cases

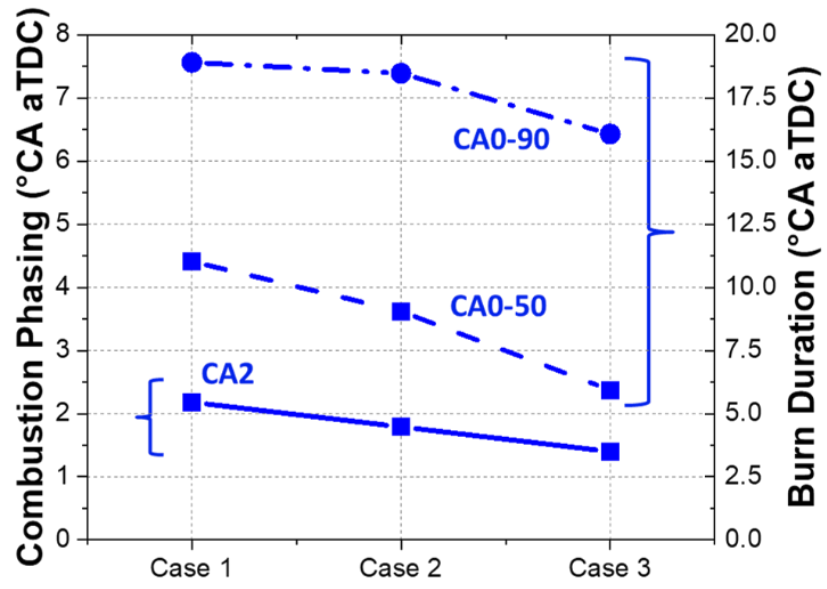

Figure 8 . The combustion phasing and burn duration for the three studied cases

\section{Energy Flow Distribution}

Figure 9 shows the complete DCEE energy distribution of brake efficiency, friction losses, heat transfer losses, and exhaust losses for all three cases. As mentioned in the methodology section, the heat transfer losses and friction losses are estimated using the Woschni equation [36] and a linear correlation [22], respectively. However, the exhaust losses are calculated using the enthalpy and temperature of the exhaust gases.

Case 3 resulted in the highest BTE, followed by Case 2 and Case 1. This follows partly from the faster combustion with an increased number of injectors, discussed earlier. Case 2 and 3 further shows reduced DCEE system heat transfer losses compared to Case 1.

This is consistent with previous studies [26-28] suggesting reduced combustion chamber heat losses, with an increased number of injectors, by reducing the gas-wall temperature gradient. Thus, due to the DCEE exhaust energy recovering capability, Case 3 increases the BTE by $1.9 \%$-points (compared to Case 1 ) with its combined fast heat release and low heat losses.

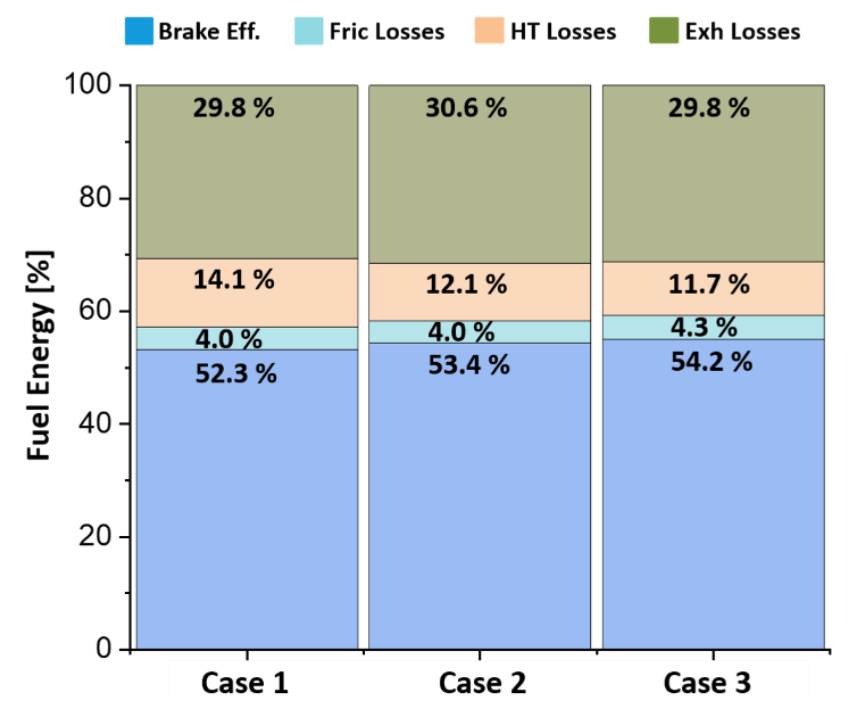

Figure 9. The energy flow distribution of the complete DCEE concept for the three studied cases

To match the in-cylinder pressure and RoHR traces for increased number of injector cases using 1D simulations, the convection heat transfer multiplier was reduced, which has resulted in lower heat losses. Figure 8 also shows that the burn duration was reduced for the three-injector case meaning the hot gases has shorter time to interact with the chamber walls for the complete combustion event. Case 3 experienced increased friction losses $(0.3 \%)$ due to its higher PCP, following from the faster heat release. Finally, Case 2 gives higher exhaust losses since not all heat transfer loss reduction renders work output in the expander unit. This is in line with the higher exhaust temperature observed for Case 2, $965 \mathrm{~K}$ instead of $950 \mathrm{~K}$ for Case 1 and 3.

Figure 10 shows how the compressor, combustor and expander divide the energy flow. The indicated stroke efficiency, friction losses for each cylinders were normalized based on the input fuel energy to the combustor unit. The compressor cylinder operates on a two-stroke cycle i.e., one revolution of the crankshaft. The first compressor stroke represents the ambient air induction from top- 


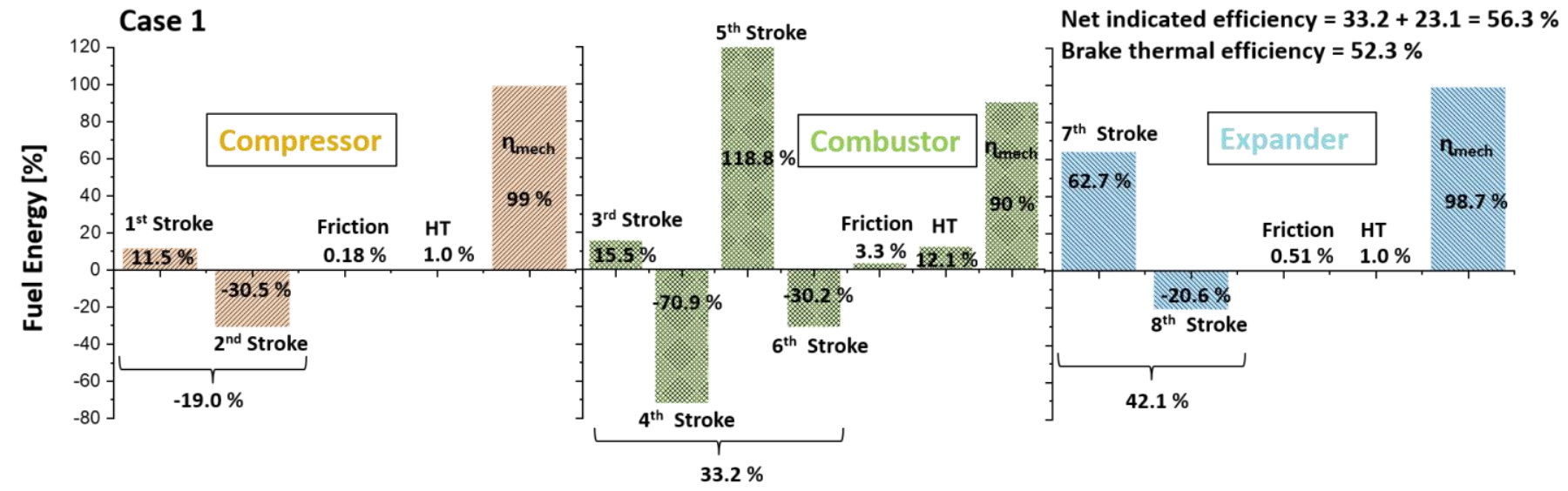

Figure 10. The breakdown of the energy flow distribution for compression, combustion and expansion cylinders of the complete DCEE concept for Case 1

dead center (TDC) to bottom dead center (BDC) and the reexpansion process after the isobaric gas transfer to equalize the incylinder pressure to ambient conditions. The second stroke indicates the compression process of the ambient air and the gas transfer to the LP tank. The compressor net indicated efficiency becomes $-19.0 \%$ here.

The combustion cylinder operates on a conventional 4-stroke cycle i.e., two revolutions of the crankshaft. The third stroke of the DCEE concept represents the compressed air induction from the LP tank. The compressed air undergoes second compression process during the fourth stroke. At the end of the fourth stroke, the fuel is injected directly in the cylinder and the combustion process commences. The high-pressure and high-temperature gases undergo the first expansion process during the fifth stroke which is then followed by the transfer of exhaust gases to the HP tank in sixth stroke. Here, the stroke efficiency for the first expansion process, i.e. $5^{\text {th }}$ stroke, resulted in over $100 \%$ indicated efficiency, keeping in mind that these calculated efficiencies are normalized based on input fuel energy. The net indicated efficiency from the combustor lead to $33.2 \%$.

The expander cylinder, like the compressor, works on a two-stroke cycle which is completed over one crankshaft revolution. The seventh stroke denotes the induction of gas from the HP tank to the expander unit followed by the second expansion process down to ambient pressure. The final, i.e., eighth stroke, denotes the expulsion of fully expanded gas to the exhaust manifold followed by a re-compression process to match the expander pressure to that of HP tank. Out of all three units, the expander cylinder showed the highest net indicated efficiency of $42.1 \%$.

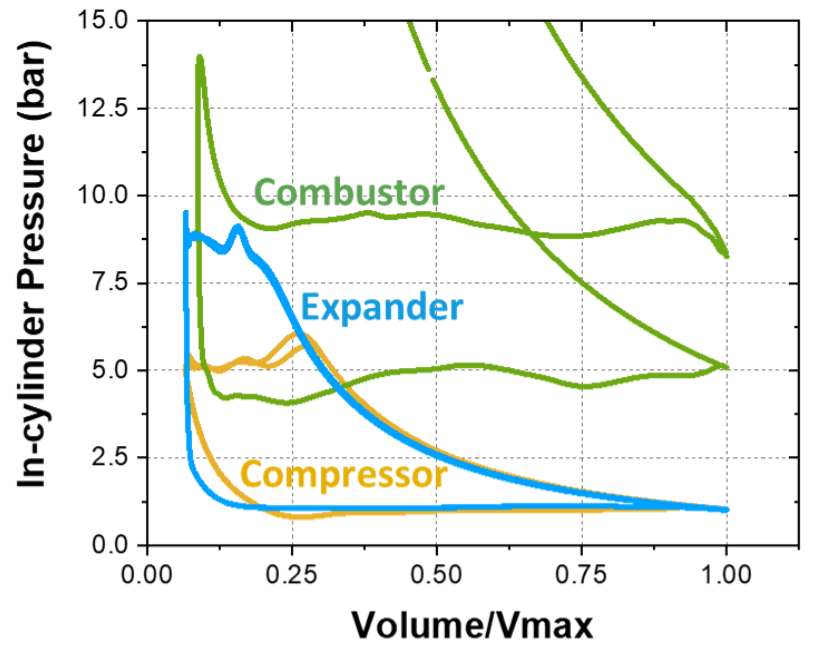

Figure 11. An example of the pressure-volume diagram for the compression, combustion and expander cylinders of the complete DCEE concept for Case 1

Around $30.2 \%$ of the exhaust energy from the combustor unit, resulted in $42.1 \%$ of expander work. The combined net indicated efficiency from the compressor-expander, i.e. low-pressure unit, is $23.1 \%$ which when added to the combustor, i.e., high-pressure unit efficiency of $33.2 \%$, resulted in an overall net indicated efficiency of $56.3 \%$.

Similar to the indicated efficiency calculation for the individual cylinders, the friction and heat-transfer losses were also normalized, as shown in Figure 10. The combustor friction losses reached the highest levels because of higher FMEP, followed by expander and compressor units. Due to lower friction losses in the compressor and expander units, a high mechanical efficiency of $\sim 99 \%$ was achieved. Noting that the expander unit was operated at a PCP of $\sim 8.7$ bar while the compressor unit functioned at a PCP of $\sim 5$ bar, as illustrated from Figure 11, compared to $\sim 166$ bar in the combustor unit (Figure 7). The displacement volume and compression ratio for compressor and expander were optimized to 

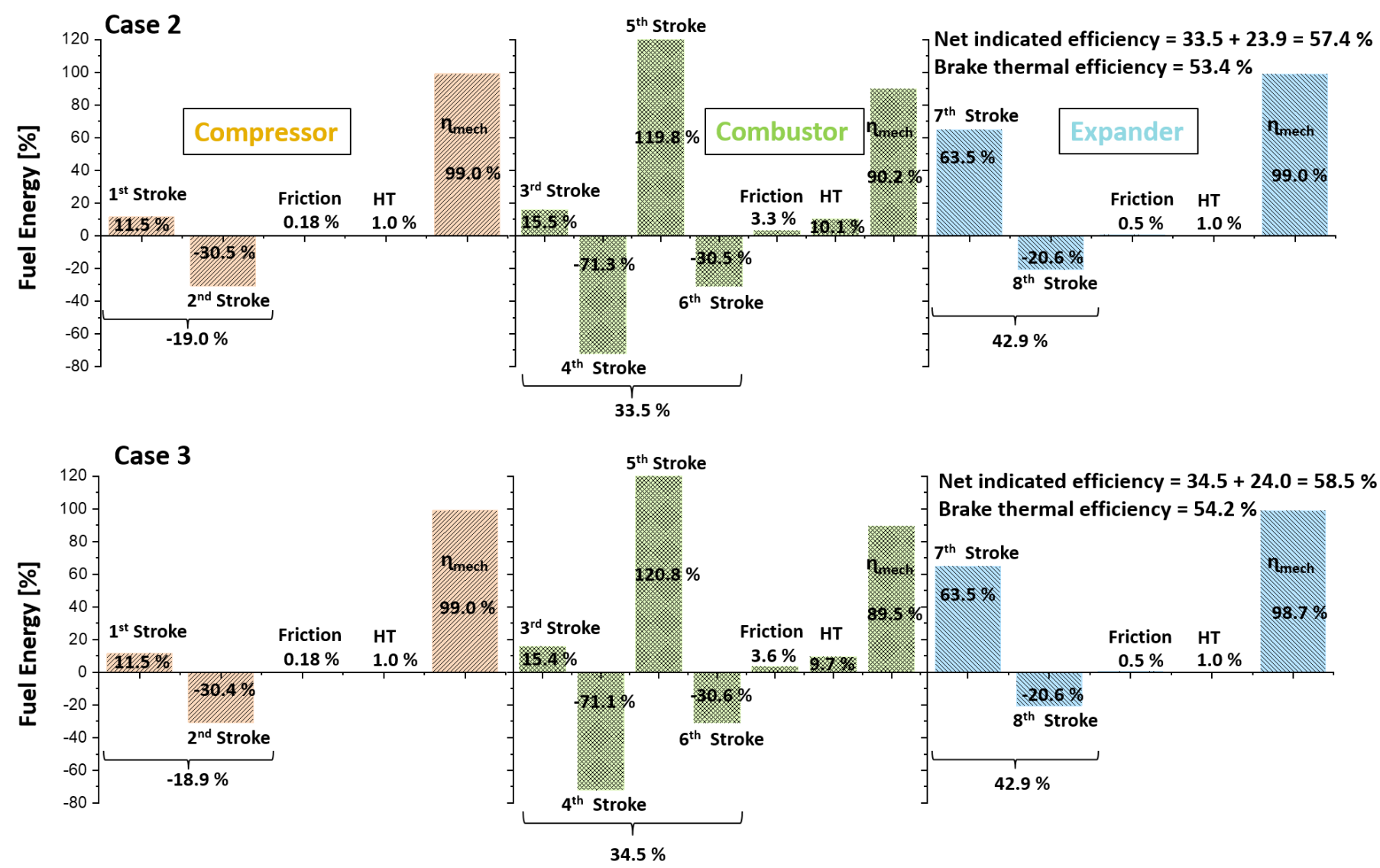

Figure 12. The breakdown of the energy flow distribution for compression, combustion and expansion cylinders of the complete DCEE concept for Case 2 (top row) and Case 3 (bottom row)

reach these PCP's (table 3), where the PCPs followed from the inlet and exhaust pressure based on the combustor CFD study.

Figure 11 highlights an in-cylinder pressure bump, during the late exhaust stroke, and low pressure levels, during the early intakestroke. This can be due to the non-optimized valve-overlap period of the combustor unit, as shown in Figure A1. Instead, the combustor lift profile and valve timings followed a standard Volvo D13 engine.

Figure 12 shows a breakdown of the energy flow distribution for Case 2 and 3.Since the compressor and expander geometrical parameters remained constant, the indicated efficiency and the friction losses did not vary much between the cases. However, the combustor unit performance differs, due to different in-cylinder pressures and RoHR Case 3 rendered the highest net indicated efficiency and BTE of $58.5 \%$ and $54.2 \%$, respectively. Compared to Case 1, Case 3 resulted in 2.2 and 1.9 percent point improvement of indicated efficiency and BTE, respectively. The heat transfer losses for Case 3 further improved 2.4 percent points, compared to Case 1. Finally, the exhaust energy conversion efficiency, from the combustor exhaust energy to expander work, increased 0.4 percent points compared to Case 1 .

Page 8 of 11

\section{Conclusions}

The present study highlighted the benefits of implementing three injectors, i.e. one central and two side-injectors for the double compression expansion engine (DCEE). Previous threedimensional computational fluid dynamics calculated the incylinder pressure and heat release rate in the DCEE combustor used as a baseline for one-dimensional GT-power simulations. The one-dimensional model included the entire DCEE system investigating how reduced heat losses from multiple injectors benefit the DCEE in terms of brake efficiency. The major conclusions drawn from this study follow as:

- Using three injectors resulted in a higher peak in-cylinder pressure and heat release rate compared to the twoinjector and single-injector cases, indicating improved mixing from a higher flow rate.

- Multiple injectors improved the DCEE brake efficiency by up to 1.9 percent points due to lower heat transfer losses combined with a faster heat release.

- The friction losses increases slightly for the three-injector case due to its higher peak pressures.

- The current DCEE model was altered to match the CFD combustion data. Increased peak in-cylinder pressure, 
different levels of intake and exhaust pressures in the combustor unit, and early or late valve timings can impact the overall efficiency analysis, suggesting a higher brake efficiency is possible, and will be considered in our future investigations.

\section{References}

1. Reitz, R.D., Ogawa, H., Payri, R., Fansler, T., Kokjohn, S., Moriyoshi, Y., Agarwal, A.K., Arcoumanis, D., Assanis, D., Bae, C., Boulouchos, K., Canakci, M., Curran, S., Denbratt, I., Gavaises, M., Guenthner, M., Hasse, C., Huang, Z., Ishiyama, T., Johansson, B., Johnson, T. V., Kalghatgi, G., Koike, M., Kong, S.C., Leipertz, A., Miles, P., Novella, R., Onorati, A., Richter, M., et al., "IJER editorial: The Future of the Internal Combustion Engine," Int. J. Engine Res. 21(1):3-10, 2020, doi: $10.1177 / 1468087419877990$.

2. Strategy for Reducing Heavy-Duty Vehicles' Fuel Consumption and CO2 Emissions, 2014.

3. ExxonMobil, "The Outlook for Energy: A View to 2040," 2018.

4. Christensen, M., Johansson, B., and Einewall, P., "Homogeneous Charge Compression Ignition (HCCI) using Isooctane, Ethanol and Natural Gas - A Comparison with Spark Ignition operation," SAE Technical Paper 972874, 1997, doi:10.4271/972874.

5. Dec, J.E., "A Conceptual Model of DI Diesel Combustion Based on Laser-sheet Imaging," SAE Technical Paper 970873, 1997, doi:10.4271/970873.

6. Dec, J.E. and Espey, C., "Chemiluminescence Imaging of Autoignition in a DI Diesel Engine," SAE Technical Paper 982685, 1998, doi:10.4271/982685.

7. Hultqvist, A., Christensen, M., Johansson, B., Richter, M., Nygren, J., Hult, J., and Aldjn, M., "The HCCI Combustion Process in a Single Cycle - Speed Fuel Tracer LIF and Chemiluminescence Imaging," SAE Technical Paper 2002-01-0424, 2002, doi:10.4271/2002-01-0424.

8. Hildingsson, L., Persson, H., Johansson, B., Collin, R., Nygren, J., Richter, M., Aldén, M., Hasegawa, R., and Yanagihara, H., "Optical Diagnostics of HCCI and UNIBUS Using 2-D PLIF of OH and Formaldehyde," SAE Technical Paper 2005-01-0175, 2005, doi:10.4271/200501-0175.

9. Splitter, D., Hanson, R., Kokjohn, S., and Reitz, R.D., "Reactivity Controlled Compression Ignition (RCCI) Heavy-duty Engine Operation at Mid-and High-loads with Conventional and Alternative Fuels," SAE Technical Paper 2011-01-0363, 2011, doi:10.4271/2011-01-0363.

10. Kokjohn, S.L., Hanson, R.M., Splitter, D.A., and Reitz, R.D., "Fuel Reactivity Controlled Compression Ignition (RCCI): a Pathway to Controlled High-efficiency Clean Combustion," Int. J. Engine Res. 12(3):209-226, 2011, doi:10.1177/1468087411401548.

11. Goyal, H. and Kook, S., "Ignition Process of Gasoline Compression Ignition (GCI) Combustion in a Small-bore Optical Engine," Fuel 256:115844, 2019,

doi:10.1016/j.fuel.2019.115844.

12. Goyal, H., Kook, S., and Ikeda, Y., "The Influence of Fuel Ignition Quality and First Injection Proportion on Gasoline Compression Ignition (GCI) Combustion in a Small-bore
Engine," Fuel 235:1207-1215, 2019, doi:10.1016/j.fuel.2018.08.090.

13. Goyal, H., Kook, S., Hawkes, E., Chan, Q.N., Padala, S., and Ikeda, Y., "Influence of Engine Speed on Gasoline Compression Ignition (GCI) Combustion in a Singlecylinder Light-duty Diesel Engine," SAE Technical Paper 2017-01-0742, 2017, doi:10.4271/2017-01-0742.

14. Goyal, H., Zhang, Y., Kook, S., Kim, K.S.., and Kweon, C.-B., "Low- to High-temperature Reaction Transition in a Small-bore Optical Gasoline Compression Ignition (GCI) Engine," SAE Int. J. Engines 12(5), 2019, doi:10.4271/0312-05-0031.

15. Goyal, H., "Double Injection Strategy in a Small-Bore Gasoline Compression Ignition Engine," The University of New South Wales, 2019.

16. Cummins, L., "Diesel's Engine: From Conception to 1918," Carnot Press, 1993.

17. Clarke, J. and O'Malley, E., “Analytical Comparison of a Turbocharged Conventional Diesel and a Naturally Aspirated Compact Compression Ignition Engine Both Sized for a Highway Truck," SAE paper 2013-01-1736, 2013, doi:10.4271/2013-01-1736.

18. Phillips, F., Gilbert, I., Pirault, J.P., and Megel, M., "Scuderi Split Cycle Research Engine: Overview, Architecture and Operation," SAE Int. J. Engines 4(1):450-466, 2011, doi:10.4271/2011-01-0403.

19. Dong, G., Morgan, R., and Heikal, M., “A Novel Split Cycle Internal Combustion Engine with Integral Waste Heat Recovery," Appl. Energy 157:744-753, 2015, doi:10.1016/j.apenergy.2015.02.024.

20. Durrett, R.P. and Gopalakrishnan, V., "Internal Combustion Engine Utilizing Dual Compression and Dual Expansion Processes," US8371256B2, United States, 2009.

21. Lam, N., Tuner, M., Tunestal, P., Andersson, A., Lundgren, S., and Johansson, B., "Double Compression Expansion Engine Concepts: A Path to High Efficiency," SAE Int. J. Engines 8(4):1562-1578, 2015, doi:10.4271/2015-01-1260.

22. Lam, N., Andersson, A., and Tunestal, P., "Double Compression Expansion Engine Concepts: Efficiency Analysis over a Load Range," SAE Technical Paper 201801-0886, 2018, doi:10.4271/2018-01-0886.

23. Lam, N., Tunestal, P., and Andersson, A., "Simulation of System Brake Efficiency in a Double CompressionExpansion Engine-Concept (DCEE) Based on Experimental Combustion Data," SAE Technical Paper 2019-01-0073, 2019, doi:10.4271/2019-01-0073.

24. Bhavani Shankar, V.S., Johansson, B., and Andersson, A., "Double Compression Expansion Engine: A Parametric Study on a High-efficiency Engine Concept," SAE Technical Paper 2018-01-0890, 2018, doi:10.4271/201801-0890.

25. Okamoto, T. and Uchida, N., "New Concept for Overcoming the Trade-Off between Thermal Efficiency, Each Loss and Exhaust Emissions in a Heavy Duty Diesel Engine," SAE Int. J. Engines 9(2), 2016, doi:10.4271/2016-01-0729.

26. Nyrenstedt, G., Alturkestani, T., Im, H., and Johansson, B., "CFD Study of Heat Transfer Reduction Using Multiple Injectors in a DCEE Concept," SAE Technical Paper 
27. Nyrenstedt, G., Houidi, M. Ben, Babayev, R., Im, H., and Johansson, B., "Computational Fluid Dynamics Investigation on Multiple Injector Concepts at Different Swirl Ratios in a Heavy Duty Engine," ASME Internal Combustion Engine Division Fall Technical Conference, 2020, doi:10.1115/ICEF2020-2933.

28. Nyrenstedt, G., Im, H., Andersson, A., and Johansson, B., "Novel Geometry Reaching High Efficiency for Multiple Injector Concepts," SAE Technical paper 2019-01-0246, 2019, doi:10.4271/2019-01-0246.

29. Nyrenstedt, G., "Multiple Injector Concepts for Compression Ignition Engines - Experimental and Computational Work for Lower Heat Losses, Increased Efficiency and Improved Combustion Control," King Abdullah University of Science and Technology, 2020, doi:10.25781/KAUST-35UP9.

30. Zeuch, T., Moréac, G., Sayeed, S., and Mauss, F., “A Comprehensive Skeletal Mechanism for the Oxidation of $n$ -heptane Generated by Chemistry-guided Reduction," Combust. Flame 155(4):651-674, 2008, doi:10.1016/j.combustflame.2008.05.007.

31. Reitz, R.D. and Diwakar, R., "Structure of High-Pressure Fuel Sprays," SAE Technical Paper 870598, 1987, doi:10.4271/870598.

32. Amsden, A.A., "KIVA-3V: A Block-Structured KIVA Program for Engines with Vertical or Canted Valves," 1997, doi:10.2172/505339.

33. Dyuisenakhmetov, A., Goyal, H., Houidi, M. Ben, Babayev, R., and Badra, J., "Isobaric Combustion at a Low Compression Ratio," SAE Technical Paper 2020-01-0797, 2020, doi:10.4271/2020-01-0797.

34. Goyal, H., Dyuisenakhmetov, A., Houidi, M. Ben, Johansson, B., Badra, J., Cenker, E., and Chang, J., "The Effect of Engine Speed , Exhaust Gas Recirculation , and Compression Ratio on Isobaric Combustion," SAE Int. J. Engines 13(5), 2020, doi:10.4271/03-13-05-0038.

35. Nhut, L., "Double Compression-Expansion Engine Concepts Experimental and Simulation Study of a Splitcycle Concept for Improved Brake Efficiency," Lund University, 2019.

36. Heywood, J.B., "Internal Combustion Engine Fundamentals," 1st ed., McGraw-Hill, New York, 1988.

37. Lam, N., Tunestal, P., and Andersson, A., "Analyzing Factors Affecting Gross Indicated Efficiency When Inlet Temperature Is Changed," SAE Technical Paper 2018-011780, 2018, doi:10.4271/2018-01-1780.

\section{Contact Information}

Harsh Goyal

Post-doctoral Fellow

Clean Combustion Research Center (CCRC)

King Abdullah University of Science and Technology (KAUST)

Building 5, 4326-WS03, Thuwal 23955-6900

harsh.goyal@kaust.edu.sa

+966544701852

\section{Acknowledgments}

The simulations are supported by the KAUST Supercomputing Laboratory (KSL) and were performed on KSL's Shaheen II supercomputer. For 3-D simulations, Convergent Science provided CONVERGE licenses while for 1-D simulations, Gamma Technologies provided GT-POWER licenses.

\section{Abbreviations}

1D - One Dimensional

3D - Three Dimensional

${ }^{\circ} \mathrm{CA}$ - Crank Angle Degree

aTDC - After Top-dead Center

BTE - Brake Thermal Efficiency

CAC - Compressed Air Cooler

CFD - Computational Fluid Dynamics

$\mathrm{CI}$ - Compression Ignition

$\mathrm{CO}_{2}$ - Carbon Dioxide

DCEE - Double Compression Expansion Engine

EGR - Exhaust Gas Recirculation

FuelMEP - Fuel Mean Effective Pressure

HCCI - Homogenous Charge Compression Ignition

$\mathrm{HP}$ - High Pressure

LP - Low Pressure

LTC - Low Temperature Combustion

$\mathrm{NO}$ - Nitric Oxide

$\mathrm{NO}_{\mathrm{x}}$ - Nitrogen Oxides

PCP - Peak Cylinder Pressure

PPC - Partially Premixed Combustion

PM - Particulate Matter

RCCI - Reactivity Controlled Compression Ignition

RoHR - Rate of Heat Release

TDC - Top Dead Center

\section{Appendix} Appendix A - Valve timing and lift profile of the
Combustion cylinder

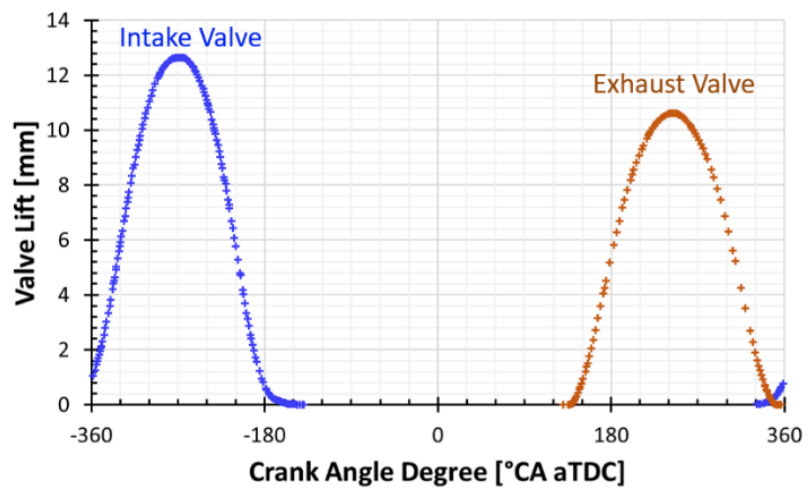

Figure A1. Intake and exhaust valve lift profiles for the combustion cylinder of DCEE concept 
Page 11 of 11 